\title{
Espaço do Grupo Opinião: vozes dissonantes sobre seu fechamento no Jornal do Brasil
}

Grupo Opinião's space: dissonant voices about its shutdow at Jornal do Brasil

Maria do Socorro Calixto Marques

Maria do Socorro Calixto Marques

Professora do PPGAC da Universidade Federal de Uberlândia

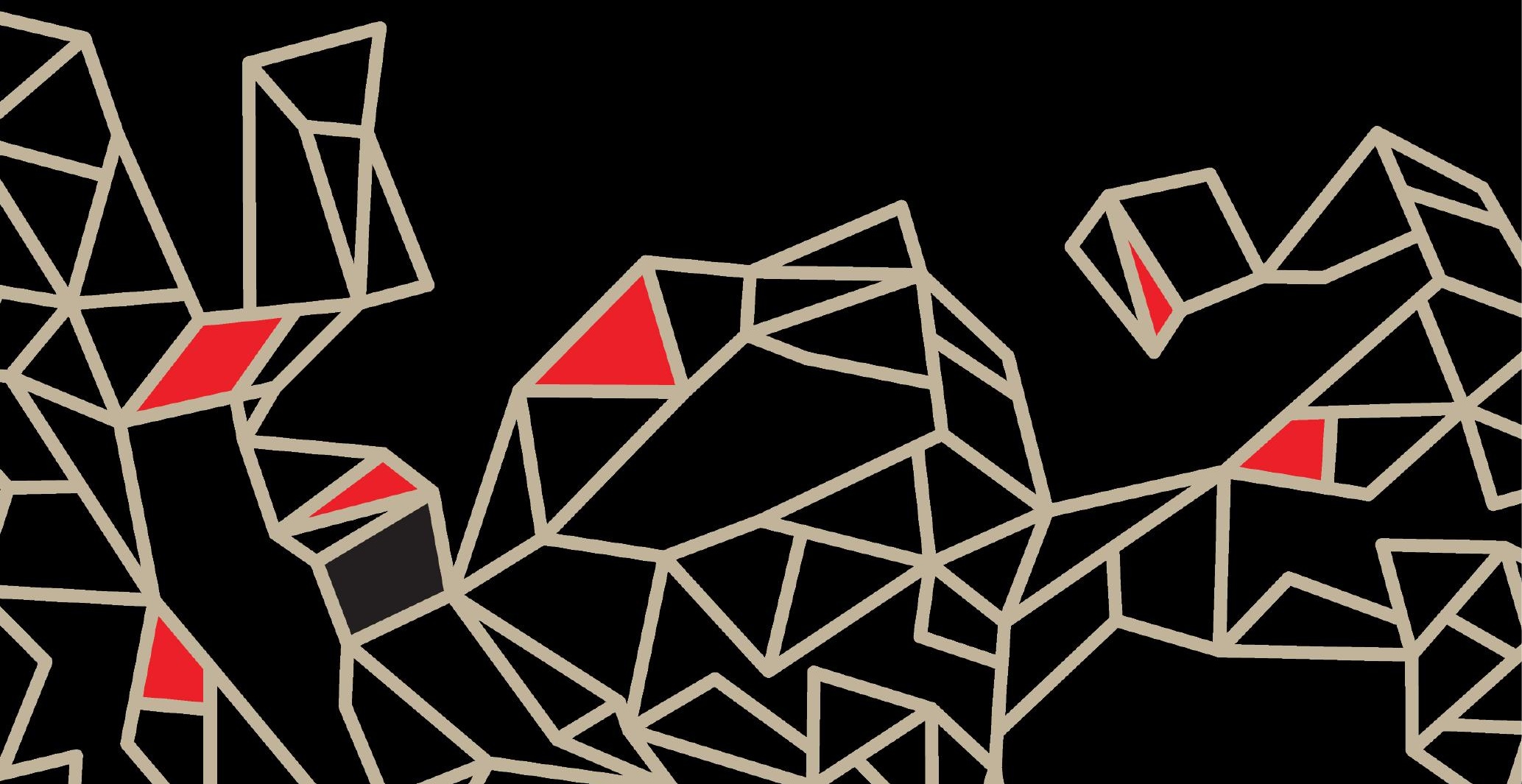




\section{Resumo}

Neste artigo proponho abordar a publicação no Jornal do Brasil, em 1980, sobre o fechamento do espaço teatral Opinião. Para analisar o material selecionado, utilizo algumas categorias teóricas sobre discurso e espaço, a exemplo de utopia, heterotopia e formação discursiva, apresentadas por Michel Foucault e Michel de Certeau no tocante a espaços construídos através de narrativas. As duas orientações teóricas apontam para a construção de um lugar como configuração de posições.

Palavras-chave: memória, espaço, Grupo Opinião, João das Neves.

\section{Abstract}

This paper aims at discussing the positions published at Jornal do Brasil (01/1980) about the shutdown of the theatrical space Opinião. The analysis of the corpus is framed on theoretical constructs about discourse and space, especially on the notions of utopia, heterotopia and discursive formation proposed by Michel Foucault and Michel de Certeau to address the spaces constructed through narratives. These two theoretical orientations consider the construction of space as a means to configure positions.

Keywords: memory, space, Grupo Opinião, João das Neves.

Sobre a interdição e venda do Grupo Opinião, retomei para esse texto matéria publicada no Jornal do Brasil em janeiro de 1980. Intitulada "Opinião, a comemoração interditada", assinada por Cleuza Maria, a reportagem registra vozes de dois sujeitos envolvidos diretamente na polêmica sobre o fechamento do espaço Opinião - João das Neves, diretor do Grupo, e Humberto Matos, chefe da Divisão de Controle e Fiscalização das Diversões Públicas do Rio de Janeiro. Os dois discursos registrados no jornal possibilitam abrir um debate sobre o lugar social de cada um dos envolvidos e como desenharam seus percursos na relação com esse espaço. Além dos dois agentes citados, há ainda locutores atores que ensaiavam a peça $O$ despertar da primavera e, como sujeitos citados, Orlando Miranda, na época diretor do Serviço Nacional 
do Teatro, e Ivan Santos, diretor da Divisão de Controle e Fiscalização das Diversões Públicas.

Embora saibamos que os registros possam ter sido descontextualizados dos pontos de vista desses sujeitos, arrisco-me a analisar seus discursos para entrever o lugar que ocuparam nessa discussão e observar como esse material serve para análise prévia do espaço físico do Opinião e do espaço construído pelos envolvidos no discurso apresentado.

A primeira informação é a de que o espaço estava ocupado com ensaios de $O$ despertar da primavera. Quando o grupo cuidava do cenário, para a estreia naquela noite, foi avisado de que o teatro não poderia abrir para o público, embora os atores pudessem continuar com os preparativos. Naquela noite, um público numeroso se viu diante das portas fechadas e de uma bilheteria que nem chegou a ser aberta.

Posteriormente, há outra informação que corresponde à ação do diretor João das Neves:

O dramaturgo João das Neves, arrendatário do Opinião, [...] explica que, há duas semana, foi procurado por dois fiscais [...] que apontaram algumas irregularidades no Teatro, "mas sem gravidade". Nessa ocasião, João das Neves foi convidado a comparecer à Divisão, para resolver o assunto.

- Expliquei a eles que iria participar de um congresso no Sul, convidado pelo MEC e que, na volta, possivelmente na segunda ou terça-feira passada, iria até lá. A viagem demorou mais do que o previsto e só quartafeira pude ir à Divisão.

Diz João das Neves que enquanto esperava para falar com o diretor, Ivan Santos Lima, foi surpreendido pela chegada de dois integrantes do elenco de $\mathrm{O}$ despertar da primavera, portando a papeleta de interdição. - Eu estava ali para tratar do assunto anterior e minha ida coincidiu com a interdição do Teatro. Na papeleta estava assinalado que o Teatro não tinha registro, alvará nem certidão de censura. [...] expliquei que as alegações eram falsas. Os documentos se encontravam na bilheteria, que só abre a partir das três da tarde. Os fiscais, porém, estiveram lá por volta das $14 \mathrm{~h}$.

[...]

- O diretor da Divisão, por sua vez, se recusou a me receber. Nesse tempo, eu já havia me comunicado com o Serviço Nacional de Teatro, que enviou para lá o assessor de Orlando Miranda, Humberto Braga. Ele também não conseguiu se recebido pelo diretor. 
[...] Depois de muito tempo, conta João das Neves, conseguiu acesso ao documento e que ele dizia em linhas gerais que as arquibancadas eram de madeira - argumento que ele contesta dizendo que muitos teatros, inclusive o Cacilda Becker, tinham arquibancadas de madeira. Outro argumento registrado no documento era a de que os banheiros para o público eram de difícil limpeza - "não entendi o que queriam dizer." E que não havia bebedouro para crianças - "não conheço um teatro brasileiro que tenha". Mais: o aspecto do teatro era feio - "não vou discutir" [...]

Outro argumento que registra a indignação de João das Neves:

- Explicaria que as arquibancadas de madeira são um elemento da mobilidade do espaço, facilitando as montagens. Mostraria que a segurança do público não está ameaçada, pois o Opinião é um dos teatros com maior facilidade de escoamento: tem um corredor imenso. Além disso tem oito extintores [...]

"Ele garante que o Opinião sofre vistoria anual do corpo de bombeiros e atende e às exigências, quando existentes. [...] O que acho estranho não é o laudo em si, mas a negativa do diretor da Divisão em ter uma conversa com a parte interessada. Isso me leva a pensar em várias hipóteses que poderiam estar por trás dessa interdição".

Fragmento a seguir da fala de Humberto Matos:

Mas o chefe e Fiscalização e diversões públicas, Humberto Matos, esclarece que a divisão não se envolve com causas mesquinhas.

- Não servimos de instrumentos a quem quer que seja. Nós seguimos a lei e cumprimos ordens de superiores. [...]

- Conhece o teatro? Aquilo ali não tem condições de funcionar. Há um laudo do Instituto Carlos Éboli condenando-o do ponto de vista de segurança e higiene. Ele continuará interditado até que isso seja resolvido. Solicitaremos também perícia do corpo de bombeiros nas arquibancadas de madeira. Alegar que eles têm extintores, eles alagam. Mas só encontrei um e com carga vencida.

Diante de dois registros que mostram os posicionamentos de um diretor teatral e de um agente de fiscalização, que, por sua vez, respalda seu discurso com um documento relacionado à vigilância sanitária, trago alguns apontamentos de Mikhail Bakhtin (1992) sobre o discurso. Ao apresentar as bases de uma teoria marxista da criação ideológica - as dos estudos sobre o conhecimento científico, a literatura, a religião, a moral etc. -, diz-nos 
que estão estreitamente ligadas aos problemas da filosofia da linguagem e, continua:

\begin{abstract}
Um produto ideológico faz parte de uma realidade (natural ou social) como todo físico, instrumento de produção ou produto de consumo; mas ao contrário destes, ele também reflete e refrata uma outra realidade, que lhe é exterior. Tudo o que é ideológico possui um significado e remete a algo situado fora de si mesmo. Em outros termos, tudo o que ideológico é um signo. (BAKHTIN, 1992, p. 31)
\end{abstract}

Considerando que cada jornal se constitui como um signo ideológico e que ocupa um lugar social é de se prever que o material publicado aponta um olhar diferente para realidades externas, melhor dizendo, para os leitores dos periódicos, no caso dessa análise - o Jornal do Brasil - as realidades externas estão relacionadas com um largo histórico cultural do espaço teatral e com uma concepção de higiene, cujo saber está associado a uma construção de mentalidade que vem do século XVIII e se espraia pelo século XIX, quando os discursos médicos associaram as condições de pobreza ao perigo (FOUCAULT apud STEPHANOU, 1997).

Além de Foucault e Bakhtin, as narrativas destacadas apontam também as ideias de Michel de Certeau (1994) sobre relatos de espaço e mais o artigo de Foucault "Outros espaços" para iluminar as análises dos relatos presentes, em especial na primeira matéria.

De Michel de Certeau (1994), valho-me da ideia de que os espaços são desenhados pelas narrativas e que esse gênero discursivo não somente desenha, mas também organiza lugares. Para tanto, o autor inicia sua apresentação trazendo a palavra grega "metaphorai" em referência aos transportes coletivos da Atenas contemporânea: "todo dia, eles atravessam e organizam lugares; eles os selecionam e os reúne num só conjunto; deles fazem frases e itinerários. São percursos de espaços" (p. 199). Para ele, as estruturas narrativas têm valor de sintaxes espaciais, esboçando com sutil complexidade os relatos cotidianos ou literários, são nossos transportes coletivos, nossas "metaphorai".

Já Foucault (2013, p. 415-424) apresenta o espaço como uma forma de relação de posições, em que a vida é comandada por espaços sacralizados. 
Também diferencia utopia de heterotopia; aquela, enquanto lugar, não é real, não tem lugar fixo, enquanto esta se refere a lugares reais, inaugurados fora daqueles que a sociedade aceita e onde impõe suas regras e condutas a serem seguidas, portanto, são denominadas por Foucault como heterotopias de desvio. Heterotopia é composta pelo prefixo heteros, de origem grega, significando o diferente, e está ligada à palavra alter (o outro), unidos a topia que significa lugar, espaço. Logo, heterotopia significa o espaço do outro.

Ao contrário da imaterialidade das utopias, que são feitas de ilusões, as heterotopias, embora localizáveis e se relacionando com todos os outros lugares, se constituem em relação a esses como espaços "de fora", diferentes e, por isso, como espaços de contraposição ao seu próprio poder.

Creio que é nesse contexto que possa situar o espaço Opinião, pelo menos naquele momento político, como espaço heterotópico, pela sua materialidade, pela sua relação com outros espaços aceitos e controlados pelas regras de conduta, pela sua oposição a essas regras, pelo seu lugar político, ideológico em relação aos outros espaços e posicionamentos. E reiterando a questão deste artigo: Qual é o espaço construído pelas vozes de João das Neves e, em especial, a de Humberto Matos?

Vejamos, um espaço localizado na zona sul do Rio de Janeiro - bairro Copacabana -, é frequentado por artistas e também por espectadores da periferia carioca. Portanto, esse lugar heterotópico se desvia do panorama geral do prédio que o abriga como também das lojas vizinhas. Assim, a exemplo do estudo que Walter Benjamin faz dos espaços conquistados pelas galerias no século XIX (1985, p. 30), a arte realizada no espaço Opinião se colocava também a serviço dos comerciantes do entorno e, possivelmente, tornou um local de atração. No entanto, segundo a voz de Humberto Matos, configuravase como um lugar precário, apoiado no laudo do Instituto Carlos Éboli, que preconizava um argumento de higiene sanitária.

Em se tratando do percurso de João das Neves no teatro brasileiro, suas circulações constroem espaços nos quais fala e faz teatro. À época viajara para Porto Alegre pelo MEC, uma instância oficial do governo, mas já havia se "ausentado" do Rio de Janeiro e fundado o Opinião-Núcleo 2 na cidade de Salvador. Acompanhando suas narrativas (ações) é possível entrever qual seu lugar na rede discursiva. Ao se ausentar do Rio de Janei- 
ro, procurando outros lugares, subloca o espaço Opinião e, posteriormente, perde o espaço.

Quanto ao relato de Humberto Matos, sua fala nos leva ao entendimento de seu posicionamento e de seu lugar no contexto de enunciação da matéria: ele não é uma pessoa de teatro, não sabe que alguns teatros até hoje têm suas arquibancadas de madeira, cortinas de veludo e mais, não conhece a história cultural do espaço Opinião ou, se conhece, essa informação é apagada de seu discurso. A ele é dada a decisão de fechar o teatro e seu discurso remete a uma ideia de "cordão sanitário" apontada por Foucault (apud STEPHANOU, 1997).

Seu discurso não prevê que sua ação, ou mataphorai - referindo-me ao relato que constrói espaço - aponta para um efeito de sentido ligado à repressão vivida pelos artistas do espaço da Siqueira Campos. Por outro lado, há uma ordem discursiva pulsante, disciplinar, que nos remete ao controle do discurso apontado por Foucault (1999).

Segundo este autor, há três processos externos de controle do discurso. O primeiro deles é a interdição (palavra proibida), que seria o mais familiar e evidente: "Não se tem o direito de dizer tudo, [...] não se pode falar tudo em qualquer circunstância, [...] qualquer um não pode falar qualquer coisa" ( $p$. 9). Penso que em 1980 falar do espaço Opinião como "aquilo ali" ou "não se envolve com coisas mesquinhas" provocaria no leitor, especialmente no leitor avisado sobre o percurso do grupo, um descontentamento, para usar um eufemismo, em relação ao lugar ocupado pelos artistas e, reiterando, a atração proporcionada pelas atividades artísticas do Opinião, que iam na contramão do que se instaurava no cenário artístico do final da década de 1980. No contexto em que foi publicada a matéria, as expressões, do ponto de vista dos ativistas, estão interditadas na ordem do discurso daqueles que tradicionalmente compunham seus espetáculos com base nas contraditórias ideias do nacional-popular.

As interdições revelam a ligação do discurso com o desejo e o poder. Foucault (1999) apresenta três tipos de interdição: 1) tabu do objeto; 2) ritual da circunstância; 3) direito privilegiado (exclusividade do sujeito que fala).

Já no segundo processo foucaultiano, a segregação opõe razão/loucura, determinando o silêncio; por exemplo, as palavras de um louco. $O$ terceiro 
e último processo, a vontade de verdade, opõe o verdadeiro/falso e se organiza ao mesmo tempo de acordo com as arbitrariedades e com contingências históricas, dessa forma a verdade é histórica. As verdades são "sustentadas por um sistema de instituições que as impõem e reconduzem [...] não se exercem sem pressão, nem sem ao menos uma parte de violência" (p. 14).

A partir desses apontamentos de Foucault, destaco as passagens dos jornais que se ajustam aos objetivos desse artigo: o que pensa um sujeito, que responde pelo setor de Fiscalização e Diversões Públicas, sobre um diretor de teatro e sobre um espaço que carrega parte da memória das atividades artísticas em anos de repressão? E mais: como o Serviço Nacional de Teatro (SNT) - na época dirigido por Carlos Miranda - atribui a fiscalização do espaço a um setor público que é responsável por espaços voltados a diversão, como parques públicos? Essas questões não terão respostas neste texto, mas apontarei um posicionamento sobre o fato de o governo fechar um espaço cultural para que um empresário o utilize para fins comerciais.

FIGURA 1 - João das Neves no teatro condenado, por enquanto, vazio

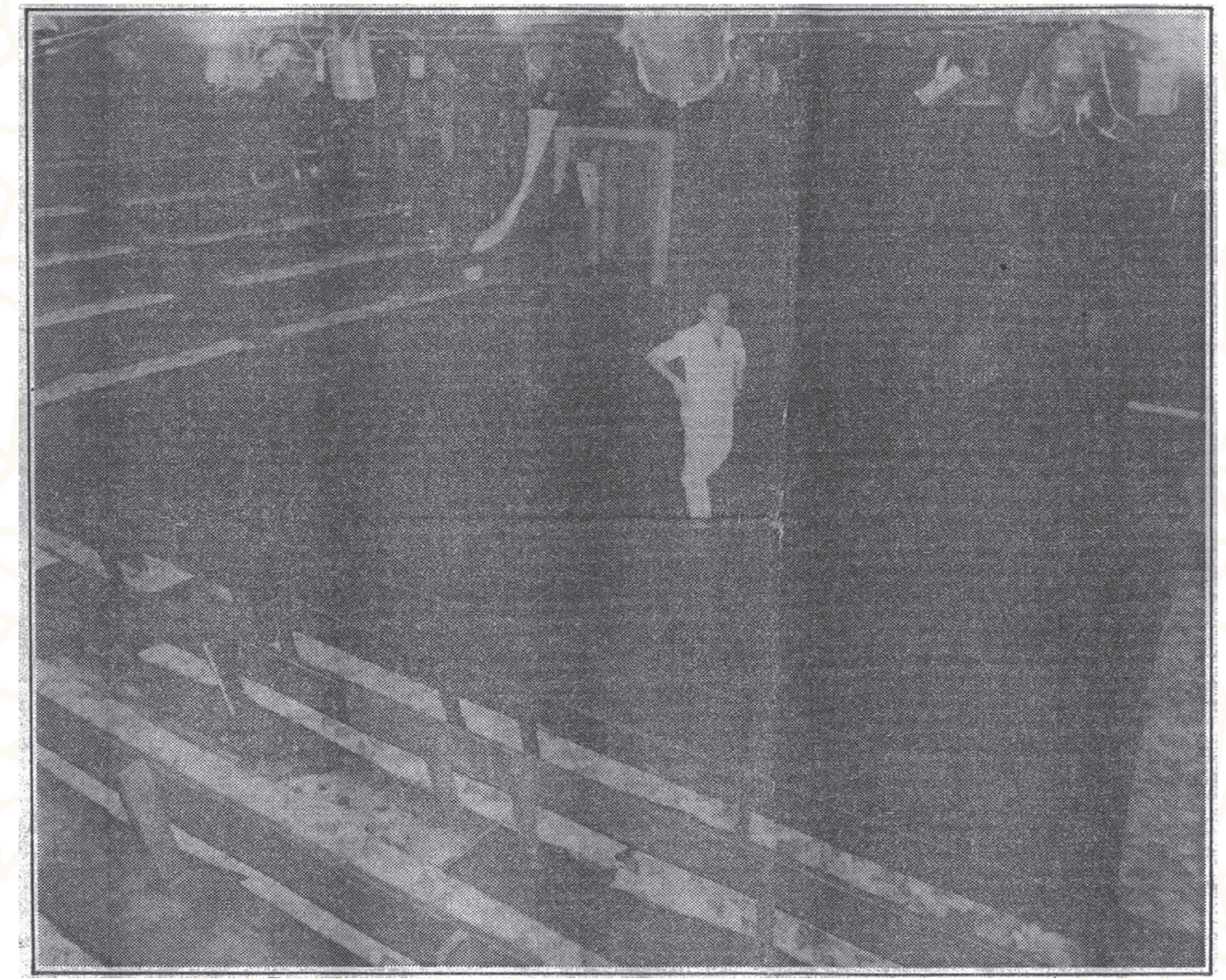

Fonte: Foto publicada no Jornal do Brasil, em 14 de dezembro de 1979. 
O Opinião que, pelo menos nessa época, é regido por homens que creem em suas utopias - as quais, segundo Foucault, são lugares irreais -, acaba criando um espaço heterotópico, real, cujo "posicionamento é em relação ao espaço real da sociedade", pois naquele momento, é o espaço que não aceita, que se contrapõe a regras e mandos do momento político. É o lugar que, somado a outros, abre para outras perspectivas, outros olhares, através de um teatro de militância e de outras experiências artísticas.

Já que o Opinião foi fechado durante o momento de abertura política, então por que fechá-lo agora, quando já não se tem mais o lugar de antes, pela mudança na política, na imprensa, no próprio teatro? Porque, ainda seguindo as reflexões de Foucault sobre formação discursiva, os conflitos e tensões vão acontecer exatamente nesse momento, quando deixa de ser um dos lugares de oposição e, de fato, passa a ser aberto, ficando expostos tensões e conflitos. Embora antes já existissem conflitos internos, a tensão se dava entre o espaço Opinião e o externo, agora, quando há convívio entre o interno e o que era externo, as relações de poder darão continuidade através de outras estratégias. Cito um recorte do autor:

Determinados posicionamentos que carregam em si a propriedade de estar em relação com todos os outros posicionamentos, mas de tal modo que suspendem, neutralizam ou invertem o conjunto de relações por eles designadas. (FOUCAULT, 2013, p. 414)

Se durante o período de ditadura a truculência do regime proibia as apresentações, quebrava, prendia e matava o outro, no caso do fechamento do Opinião, a estratégia é o apelo às questões de higiene, de segurança e estética. É como se fosse possível, enfim, apreender uma utopia, sem lugar fixo, do passado, na sua representação heterotópica para que dela não sobre nenhum fantasma a assombrar os novos tempos.

O Opinião tendo seu lugar criado pela utopia se transforma em espaço heterotópico, que pode ser isolado, mais ainda, extirpado na sua materialidade, por um discurso registrado no jornal - o de Humberto Matos - permeado de inconsistências, incoerências, incompletudes, pois, conforme as palavras de João das Neves em relação ao teatro ser feio, "não vou discutir"; se é difícil limpar os banheiros - "não entendi". Enfim, o discurso de Humberto Matos res- 
gata a voz de Carlos Éboli - homenageado pelo Instituto, aqui tomado fora de seu contexto. Éboli, quanto ao fato de limpar e conservar a praça onde residia, justificava sua atitude em função "da higiene, da formosura e do progresso deste magnífico torrão".

O discurso de Humberto Matos faz pensar na expressão "cordão sanitário" em dois momentos, ambos correlacionados com o Opinião. A expressão utilizada na Idade Média fazia alusão a uma demarcação que isolava dos sadios aqueles que possuíam doenças contagiosas, como a lepra, e, depois, durante a Guerra Fria, foi retomada para explicar a política em países do entorno da União Soviética, de forma a isolar o "vírus" comunista que poderia contaminar o planeta.

Portanto, apelar para as condições de higiene, uma vez que a ditadura já havia acabado, legitimava o fechamento do Opinião, levando-o ao ostracismo. Não combinava com o desejo de progresso capitalista, um lugar que historicamente foi ponto de subversão e que agora é feio, sinônimo de pobre. O Opinião não combinava mais com a euforia modernizadora, o desejo de modernidade, a vontade de outra verdade e penso nas palavras de Sergio de Carvalho (2002) quando registra sua entrevista sobre a mudança de paradigma nos processos de criação espetacular:

A arte teatral, do início dos anos 1980 até meados de 1990, e estou considerando aqui a parte mais inventiva da produção, tornou-se um ambivalente campo de representações atemporais, de teor lírico, algo expressionista, fazendo o pêndulo entre a arquetipia mítica e a ruína de um futuro inatingível. Tudo o que fosse sem espaço e sem tempo definidos tudo que se envolvesse numa carapaça estética abstrata era considerado de bom gosto, interessante, renovador. O contrário disso - a forma concreta, histórica e social - era visto como empedernido. (p. 90)

O espaço Opinião estava, portanto, fora dos padrões de higiene, de estética e do progresso desse magnífico torrão.

\section{Referências bibliográficas}

BAKHTIN, M. Marxismo e filosofia da linguagem. Tradução Michel Lahud e Yara Frateschi Vieira. São Paulo: Hucitec, 1992. 
BENJAMIN, W. Paris, capital do século XIX. In: KOTHE, F. (Org.). Walter Benjamin: sociologia. São Paulo: Ática, 1985. p. 30-43.

CARVALHO, S. Entrevista. In: GARCIA, S. Odisseia do teatro brasileiro. São Paulo: Editora Senac, 2002.

CERTEAU, M. de. Relatos de espaço. In: A invenção do cotidiano. Petrópolis: Vozes, 1994.

FOUCAULT, M. A ordem do discurso. Trad. Laura Fraga Sampaio. São Paulo: Loyola, 1999.

Outros espaços. In: Estética, literatura e pintura, música e cinema. (Coleção Ditos e Escritos III). Rio de Janeiro: Forense Universitária, 2013.

MARIA, C. OPINIÃO, a comemoração interditada. Jornal do Brasil, Rio de Janeiro, 25 jan. 1980.

SOUZA, M. G. de. A gestão de Orlando Miranda no SNT e os paradoxos da "hegemonia cultural de esquerda". Disponível em: <http://www.snh2011.anpuh.org/ resources/anais/14/1307372359_ARQUIVO_GARCIA.ComunicacaoANPUH-SP -2011\%28ART\%29.pdf>. Acesso em: 12 jan. 2015.

STEPHANOU, M. Práticas Educativas da medicina social: os médicos se fazem educadores. História da Educação, ASPHE/FaE/UFPel, Pelotas, v. 1, n. 2, p. 145168, set. 1997. Disponível em: <//seer.ufrgs.br/asphe/article/viewFile/30670/pdf>. Acesso em: 7 jan. 2015.

Recebido em 14/03/2015

Aprovado em 23/05/2015

Publicado em 30/06/2015 